\title{
Chk1-cyclin A/Cdk1 axis regulates origin firing programs in mammals
}

\author{
Makoto Nakanishi • Yuko Katsuno • \\ Hiroyuki Niida $\cdot$ Hiroshi Murakami • \\ Midori Shimada
}

Published online: 15 December 2009

(C) Springer Science+Business Media B.V. 2009

\begin{abstract}
DNA replication is key to ensuring the complete duplication of genomic DNA prior to mitosis and is tightly regulated by both cell cycle machinery and checkpoint signals. Regulation of the $\mathrm{S}$ phase program occurs at several stages, affecting origin firing, replication fork elongation, fork velocity, and fork stability, all of which are dependent on S-phase-promoting kinase activity. Somatic mammalian cells use well-established origin programs by which specific regions of the genome are replicated at precise times. However, the mechanisms by which $\mathrm{S}$ phase kinases regulate origin firing in mammals are largely unknown. Here, we discuss recent advances in the understanding of how $\mathrm{S}$ phase programs are regulated in mammals at the correct regions and at the appropriate times.
\end{abstract}

Keywords DNA replication - S phase program . cyclin $\cdot$ cyclin dependent kinase $(\mathrm{CDK}) \cdot$ checkpoint protein $1(\mathrm{Chk} 1)$

$\begin{array}{ll}\text { Abbreviations } \\ \text { ATR } & \text { AT and Rad3-related } \\ \text { ATRIP } & \text { ATR-Interacting Protein }\end{array}$

Responsible Editors: Marie-Noëlle Prioleau and Dean Jackson.

M. Nakanishi $(\bowtie) \cdot$ Y. Katsuno $\cdot$ H. Niida $\cdot$ H. Murakami $\cdot$

M. Shimada

Department of Cell Biology,

Graduate School of Medical Sciences,

Nagoya City University,

1 Kawasumi, Mizuho-cho, Mizuho-ku,

Nagoya 467-8601, Japan

e-mail: mkt-naka@med.nagoya-cu.ac.jp
ATM Ataxia-Telangiectasia-Mutated
BRCT BRCA1 C Terminus
CIdU Chlorodeoxyuridine
DSBs Double Strand Breaks
GCN5 General Control Nonrepressed 5
IdU Iododeoxyuridine
$\mathrm{Mcm} \quad$ Minichromosome maintenance
MEFs Mouse Embryonic Fibroblasts
PIKK PI3 Kinase-related Kinases
RPA Replication Protein A
Tip60 Tat-interactive protein, $60 \mathrm{kDa}$
TopBP1 Topoisomerase Binding Protein 1
$\beta$-TRCP $\beta$-Transducin Repeat-Containing Protein 1

\section{Introduction}

Duplication of the eukaryotic genome is regulated at multiple stages including the initiation of DNA replication and the origin firing program as well as during replication fork progression and in the control of fork velocity. DNA replication in mammals is initiated at a great number of origins throughout the genome. Mammalian DNA replication is characterized by a high order of uncertainty due to the existence on the genome of hundreds to thousands of potential origins that fire with varying efficiencies and at different times. However, spatial and temporal patterns of DNA replication in mammals are relatively well defined, and distinct patterns of replication foci appear as cells progress from early to late $\mathrm{S}$ phase 
(Jackson 1995). A single replication factory is actually comprised of several candidate origins, most of which are not normally used since firing of one origin inhibits activation of any other Mcm2-7 complex within the same factory (Woodward et al. 2006). Thus, S phase programs appear to be mediated in two distinct ways; one via the activation of replicon clusters and the other, through the selection of one Mcm2-7 complex within a single replicon.

According to the replicon model, DNA replication is regulated through interaction between cis-acting sequences termed replicators and trans-acting initiation factors known as initiators. With trans-factors, for example, initiation of early origin firing is regulated by cyclin A- or cyclin E-associated Cdk2 activities in normal somatic cells. In addition, $\mathrm{Cdc} 7$ activity is also reported to be involved in the regulation of $\mathrm{S}$ phase entry. These two kinases are involved in the loading on origins of $\mathrm{Cdc} 45$ by phosphorylating subunits of Mcm2-7 complex (Machida et al. 2005). In budding yeast, Cdk phosphorylation of an initiation factor, Sld2/Drc1, is also critical for the initiation of DNA replication (Masumoto et al. 2002). In contrast to those involved in early origin firing, trans-factors that regulate late origin firing have been less clearly identified, although Clb5-dependent Cdk activity is known to be indispensable for activation of late replication origins in budding yeast (Donaldson et al. 1998; Noguchi et al. 2002). These results suggest the existence of a specific trans-factor(s) for late origin activation as there is for early origin. Therefore, our primary aim in this review is to focus on recent findings regarding late origin firing in eukaryotes while emphasizing the components and events that are specific to metazoans.

\section{PIKK kinases are essential for proper timing of late origin replication firing}

Although DNA replication is initiated at specific sequence elements in prokaryotes or budding yeast (Stinchcomb et al. 1979), such sequence-specific initiation does not appear to be required in metazoans (DePamphilis 2003). Instead, origin firing is likely dependent on stochastic initiation at dormant origins defined as such be their chromatin status (Gilbert 2004), despite the presence of some origins that are sequence specific (Huberman 1998). Stochastic initia- tion is organized by feedback regulation from active replicons, which is mediated by the sensing of ongoing replication (Ge et al. 2007; Ibarra et al. 2008). In the Xenopus laevis egg system, these ongoing replication events appear to be sensed by the DNA-damage checkpoint kinases ataxia telangiectasia mutated (ATM) and/or AT and Rad3 related (ATR) because inhibition of ATM and ATR with caffeine or specific neutralizing antibodies promoted rapid and synchronous origin firing (Shechter et al. 2004). ATM and ATR kinases are both extremely large proteins that phosphorylate a great number of substrates. Patients bearing an ATM mutation suffer from a devastating syndrome called ataxia telangiectasia that causes immunodeficiency, genomic instability, clinical radiosensitivity, and a predisposition to cancer (Shiloh 1997). Although cells lacking ATM are viable, suggesting that $A T M$ is a non-essential gene for normal cell cycle progression and development, its kinase activity is strongly stimulated by double strand breaks (DSBs). The identification of a damage-induced phosphorylation site (Ser1981) revealed a new mechanism for ATM regulation by which a rapid and sensitive switch for checkpoint signaling is permitted (Bakkenist and Kastan 2003). ATM under unperturbed conditions exists as a homodimer complex with its kinase active site physically blocked by tight intermolecular binding to a protein domain around Ser1981. In response to DSBs, a conformational change in the ATM protein stimulates it to auto-phosphorylate Ser1981 in an intermolecular manner. In contrast, the auto-phosphorylation of ATM at Ser1981 is suppressed under unperturbed conditions by a constitutive interaction with PP2A that dephosphorylates Ser1981 (Goodarzi et al. 2004). Acetylation of ATM by Tip60 is also reported to be important for its full activation (Sun et al. 2005).

ATR was discovered from its sequence similarity to ATM and Rad3, and was shown to play an essential role in DNA damage and DNA replication checkpoint activation. Mutations in the ATR gene have been reported in a subset of patients with Seckel syndrome (O'Driscoll et al. 2003), which is a human autosomal recessive disorder causing severe intrauterine growth retardation, proportionate dwarfism, microcephaly, with skeletal and brain abnormalities, and a predisposition to cancer. ATR constitutively forms a heterodimer with ATRIP that binds to UV-damaged DNA or to replication protein A (RPA)-coated single-stranded DNA (Zou and 
Elledge 2003). TopBP1 is another protein that acts in response to DNA damage. TopBP1, a mediator protein containing eight BRCT phospho-recognition motifs, binds and activates ATR/ATRIP complexes in a manner distinct from its role in the initiation of DNA replication (Kumagai et al. 2006). TopBP1 binds to the constitutively phosphorylated C-terminal tail of Rad9 on the 9-1-1 complex at damaged sites, and this binding occurs via its first pair of BRCT repeats. Therefore, although the precise physical mechanisms by which the interactions between TopBP1 and ATRATRIP elicit increased ATR activity remain to be determined, TopBP1 appears to be implicated in early events in signaling following recruitment of ATRATRIP to sites of DNA damage and replication stress. Involvement of ATM and ATR in the mammalian origin firing program was also proposed from the observations that UV irradiation induced inhibitory effects on initiation of SV40 DNA replication as well as replication of cellular chromosomes in intact cells (Miao et al. 2003). The essential role of ATM and ATR in the origin firing program is further supported by the following observations: (1) ATR is activated during unperturbed $\mathrm{S}$ phase in the absence of DNA damage via replication intermediates containing RPA-bound single-stranded DNA (ssDNA) and this occurs in a manner dependent on the Rad9-Rad1-Hus1 (9-1-1) complex (Niida et al. 2007; Sorensen et al. 2004). Furthermore, the activation of ATR slows down the rate of DNA replication by blocking origin firing. (2) Inhibition of ATM and ATR by caffeine or neutralizing antibodies speeds up the rate of DNA replication (Marheineke and Hyrien 2004; Shechter et al. 2004). The effect of caffeine in promoting increased origin firing appears partly the result of feedback from ssDNA-RPA intermediates since partial depletion of RPA from Xenopus egg extracts prevents an increase in the number of origin firings. (3) Cells derived from an AT patient were observed to replicate more quickly than wild-type cells (Painter and Young 1976). Intriguingly, DNA replication checkpoint or S phase DNA damage checkpoint systems were reported to be involved in the origin firing program in vertebrate cells (Willis and Rhind 2009). Therefore, hyperactivation of ATM and ATR by stalled DNA replication or DNA damage during $\mathrm{S}$ phase is likely to suppress further origin activation.

Checkpoint inhibition of origin firing is by necessity a global response to DNA damage or stalled replication forks. Given that low doses of IR inhibit origin clusters that are not necessarily directly impacted by DNA damage and that episomal DNA synthesis is prevented even when only nuclear DNA is damaged by IR (Cleaver et al. 1990; Lamb et al. 1989), checkpoint components must act at origins distant from sites of DNA damage to prevent origin firing. These results clearly indicate that ATM and/or ATR play an essential role in the origin firing program under unperturbed and perturbed conditions and that origin regulation is a global response in which ATM and/or ATR act in trans in response to DNA lesions that may be far from the origins being regulated.

\section{Chk1 but not Chk2 is a regulator of the origin firing program functioning downstream of PIKK kinases}

With downstream targets, both ATM and ATR are capable of specifically phosphorylating serine or threonine residues in SQ/TQ sequences (Matsuoka et al. 2007), sharing common downstream substrates such as p53 and BRCA1 although they primarily respond to different stimuli (Harper and Elledge 2007). Recently, large-scale proteome analysis revealed that ATM phosphorylates hundreds of substrates that function in cell cycle regulation, DNA repair, checkpoints, and apoptosis (Matsuoka et al. 2007). Of these, the checkpoint kinases Chk1 and Chk2 are probable candidates as trans-acting regulators of origin firing. Chk1 and Chk2 were first identified in fission yeast as essential for cell cycle arrest prior to mitosis in response to DNA damage or DNA replication blockage, respectively. These kinases were also identified in vertebrate cells based on their homology with fission yeast orthologues (Niida and Nakanishi 2006). Chk1 is phosphorylated at Ser317 and Ser345 by ATR in response to DNA damage or DNA replication stress. This phosphorylation is blocked in cells lacking the kinase ATR and markedly inhibited in cells with a reduced amount of Rad17 or lacking Hus1. Chk1 is a constitutively active enzyme and ATR/ATM-dependent phosphorylation appears not to regulate its kinase activity but rather its subcellular localization. For example, in undamaged cells, a significant proportion of Chk1 is chromatin-associated and ATR/ATMdependent (Niida et al. 2007; Smits et al. 2006). Chk1 phosphorylation following DNA damage results 
in its rapid dissociation from chromatin, allowing phosphorylation of targets in the nuclear-soluble fraction.

One of the major downstream targets of Chk1 is a family of Cdc 25 phosphatases that catalyze dephosphorylation of the inhibitory cdk1 and cdk2 at T14 and Y15, thereby initiating their kinase activity. Studies in yeasts, Xenopus, and mammals have demonstrated that phosphorylation of these Cdc25 proteins by Chk1 creates binding sites for 14-3-3 proteins and downregulates their phosphatase activities. In addition to 14-3-3 binding, in the presence of DNA damage during $\mathrm{S}$ phase progression, activated ATR-Chk1 phosphorylates Cdc25A at Ser124 and Thr507, leading to recruitment of 14-3-3 protein as well as at Ser76 triggering its ubiquitination and degradation (Mailand et al. 2000). Downregulated Cdc25A suppresses cdk2 and cdk1 activation that blocks the loading onto chromatin of Cdc45 (Zou and Stillman 1998), a protein required for the initiation of DNA replication through incorporation of DNA polymerase alpha into pre-replication complexes.

Analyses using mice deficient in Chk1 revealed its essential role in early embryonic development (Takai et al. 2000). Use of Chk1-deficient ES cells showed that Chk1 is required for cell cycle arrest before mitosis in response to DNA damage or a DNA replication block (Niida et al. 2005). In addition to its involvement at checkpoints, Chk1, similar to ATR, plays a role at every point in the cell cycle and loss of Chk1 results in the premature onset of mitosis through the dephosphorylation of cdk1 at Tyr15. Premature mitosis leads to the activation of caspases 3 and 9 triggered by cytoplasmic release of cytochrome $\mathrm{c}$ and the subsequent mitotic catastrophe. In contrast to Chk1-deficient embryonic cells, Chk1-depleted or Chk1-inhibited somatic mammalian cells or chicken cells exhibit gross abnormality in $\mathrm{S}$ phase (MayaMendoza et al. 2007; Petermann and Caldecott 2006; Petermann et al. 2006), reflecting increased origin activation, a slow rate of fork progression, and a loss of temporal continuity within the replication program. The abnormal $\mathrm{S}$ phase program likely results in an increased number of chromosome breakages that appear as gH2AX foci. The importance of Chk1dependent $\mathrm{S}$ phase regulation is emphasized by the phenotype of Chk1-heterozygous cells from transgenic mice. Such cells provide three clear phenotypes of haplo-insufficiency associated with tumorigenicity in vivo including inappropriate $\mathrm{S}$ phase entry, accumulation of DNA damage and failure to restrain mitotic entry (Lam et al. 2004).

Chk1 also plays an important role in transcriptional regulation of the genes involved in $\mathrm{S}$ phase progression (Shimada et al. 2008). Chromatin-bound Chk1 phosphorylates histone H3-threonine 11 (H3-T11). Phosphorylation of H3-T11 significantly enhances the binding affinity between GCN5 histone acetyltransferase and histone tails. Thus, changes in the phosphorylation status of $\mathrm{H} 3-\mathrm{T} 11$ in response to DNA damage likely influence GCN5 recruitment at promoters and consequently, transcription of GCN5dependent genes. GCN5 is utilized as an auxiliary acetyltransferase for E2Fs which regulate the expression of the many genes involved in DNA replication. In addition, GCN5 is recruited to the promoters of many cell cycle genes and GCN5-deficient cells have been shown to exhibit a significant decrease in their growth, which is associated with a reduction in the expression of many cell cycle regulatory genes. Therefore, Chk1-dependent repression of GCN5dependent gene expression serves as an alternative checkpoint mechanism to promote cell cycle delay or arrest, in addition to the regulation of inhibitory Y15 phosphorylation of cdk1 and $\mathrm{cdk} 2$. Consistent with this, $\mathrm{Chk}^{-/-}$somatic cells permanently arrest the cell cycle at middle $\mathrm{S}$ phase, preventing analysis of the $\mathrm{S}$ phase program in $\mathrm{Chk}^{--}$cells. Using the Cre/loxP system, we carefully synchronized Chk $1^{\mathrm{del} /-}$ MEFs at $\mathrm{S}$ phase onset and analyzed their spatiotemporal replication site patterns during early to middle $\mathrm{S}$ phase (Katsuno et al. 2009). Double-labeling of cells with IdU and CIdU revealed that Chk1 depletion in mammals resulted in aberrant origin firing as observed in avian cells (Fig. 1). Molecular combing of single DNA molecules demonstrated that Chk1 depletion resulted in a clear reduction in origin spacing ( $40 \%$ of control cells) as well as in the rate of fork elongation throughout the labeling period. However, since slowing the replication speed very rapidly triggers the recruitment of latent origins (Courbet et al. 2008), it is not clear at this stage whether Chk1 regulates either or both activation of origins or fork velocity. Molecular combing also revealed that loss of Chk1 frequently stalls and collapses active forks.

Intriguingly, ChIP analysis of early S phase cells using FACS-based cell sorting clearly demonstrated that the relative amounts of nascent DNA around 

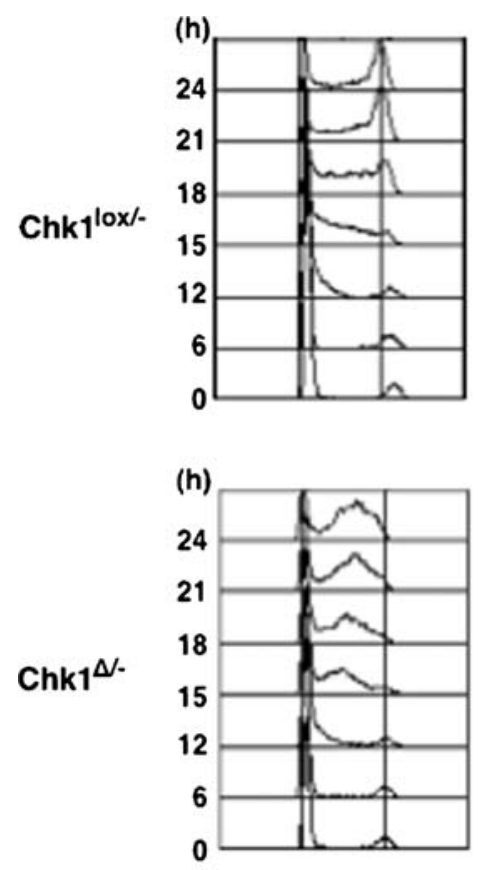

Fig. 1 Chk1 depletion results in an aberrant $\mathrm{S}$ phase program. Chk $1^{\text {lox } /-}$ MEFs and Chk $1^{\mathrm{del} /-}$ MEFs were synchronized at quiescence by serum starvation and then released into G1 phase by the addition of $15 \%$ serum. Cells were harvested at the indicated times and their cell cycle distribution was analyzed by FACS (left panels). Replication sites were pulse-labeled for 10 min with BrdU and analyzed by fluorescence microscopy.

early replication sites in Chk $1^{\mathrm{del} /-}$ cells were almost the same as those in control cells, whereas those of late replication in $\mathrm{Chk} 1^{\mathrm{del} /-}$ cells were significantly higher than those in control cells. Thus, loss of Chk1 is likely to induce abnormal firing of late origins at early $\mathrm{S}$ phase.

Unlike Chk1, Chk2 does not appear to be involved in the $\mathrm{S}$ phase program, and is dispensable for normal cell survival, cell proliferation, and prenatal development (Takai et al. 2002). Interestingly, heterozygous germline mutations in the human Chk2 gene have been found in a subset of patients with Li-Fraumeni syndrome, a familial type of cancer, without any p53 mutation, suggesting its role as a bona fide tumor suppressor. Chk2 is mainly activated by phosphorylation of its Thr68 in an ATM-dependent manner in response to DSBs. Although biochemical analyses revealed that activated Chk2 is capable of phosphorylating Cdc25A at Ser123, Cdc25C at Ser216, BRCA1 at Ser988, and p53 at several sites, including Ser20,
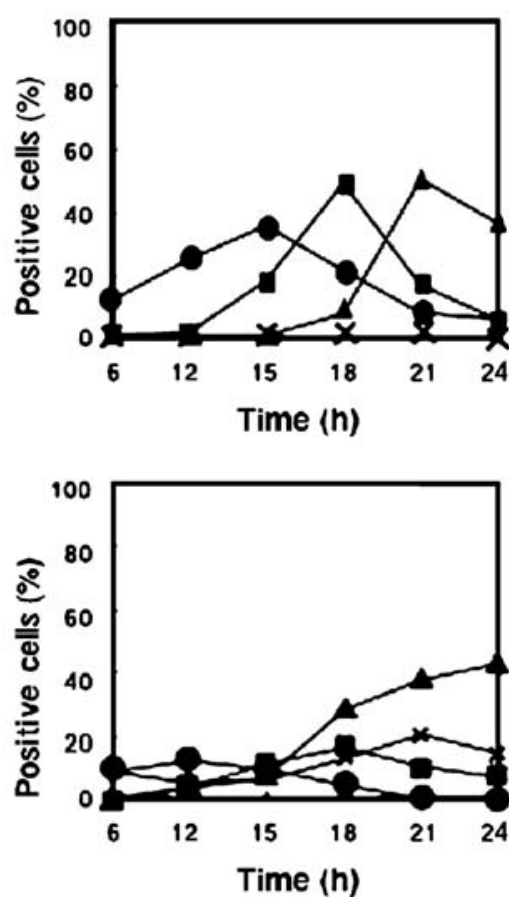

Typical replication site patterns at the indicated times were classified according to a previous study. The number of replication sites in a typical pattern was counted and the positive cells relative to the total number of cells is expressed as a percentage (right panels). Filled circles represent the early pattern, filled squares the middle pattern, filled triangles the late pattern, and $x$, the mixed pattern

examination of Chk2-deficient mice and their cells showed that this enzyme functions mainly in $\mathrm{p} 53$ dependent apoptosis and DNA repair, but not in cell cycle arrest in response to DNA damage. Chk2deficient mice are resistant to IR as a result of the preservation of splenic lymphocytes, thymocytes, and neurons of the developing brain whose apoptosis is known to be p53-dependent. However, ATM-Chk2 signaling at the intra-S phase checkpoint in response to IR is considered to be important since phosphorylation of Cdc25A by Chk2 was reported to trigger its ubiquitination and degradation in vitro (Falck et al. 2001). However, Chk2 fails to phosphorylate Cdc $25 \mathrm{~A}$ at Ser76 whose phosphorylation is mainly mediated by Chk1 (Jin et al. 2008), which leads to the formation of a phospho-degron that is recognized by the ubiquitinligase, b-TRCP. Consistent with this, use of Chk2deficient cells showed that Chk2 is not essential for the intra-S phase checkpoint response. In addition, Chk2deficient MEFs do not show any $\mathrm{S}$ phase program 
abnormalities (Nakanishi et al. unpublished results). Thus, the role of Chk2 in the $\mathrm{S}$ phase program remains questionable.

The observation that Chk1 is phosphorylated during unperturbed $\mathrm{S}$ phase, which regulates the activity and stability of $\mathrm{Cdc} 25$ and results in the inactivation of Cdks through increased phosphorylation of their Y15 residues, leads us to speculate that Chk1 regulates the origin firing program through its involvement in certain cyclin-Cdk activities.

\section{Cyclin A-Cdk1 complex regulates the origin firing program, but not replication fork stability in mammalian cells}

In yeast, the same Cdk catalytic subunit triggers both DNA replication and mitosis, and this versatility is achieved in part by binding different cyclins that confer distinct substrate specificities. In contrast, multiple Cdk subunits in metazoans pair with preferred cyclin partners to execute specific functions in cell cycle progression. For example, Cdk2 binds with cyclins $\mathrm{E}$ and $\mathrm{A}$ to promote $\mathrm{S}$ phase, and Cdk1 binds with cyclins $\mathrm{A}$ and $\mathrm{B}$ to complete $\mathrm{S}$ phase and trigger mitosis. It remains to be determined whether the Chk1-Cdc25 axis regulates a particular set of cyclinCdk complexes or multiple cyclin-Cdk complexes to complete the $\mathrm{S}$ phase program. Clb5-dependent $\mathrm{Cdk}$ activity was found to be indispensable for activation of late origins in budding yeast, showing that Clb5deficient cells failed to activate these origins and subsequently showed an extended S phase (Donaldson et al. 1998). Interestingly, this late origin firing defect is suppressed although entry into $\mathrm{S}$ phase and is significantly delayed in $\mathrm{Clb5/Clb6}$ double-mutant cells, suggesting that other B-type cyclins promote firing of both early and late replication origins. These observations regarding budding yeast strongly suggest that specific trans-regulators of late origin activation also exist in other eukaryotes.

We found that in normal MEFs, cyclin A2-Cdk1 activity first appeared at middle $\mathrm{S}$ phase and increased thereafter, whereas cyclin A2-Cdk2 activity was detected at early $\mathrm{S}$ phase (Katsuno et al. 2009). These results are consistent with those of a recent study using centrifugal cell elutriation which showed that cyclin A assembles with Cdk1 only after complex formation with $\mathrm{Cdk} 2$ reaches a plateau during late $\mathrm{S}$ and G2 phases (Merrick et al. 2008). Importantly, cyclin A2-Cdk1 activity was detected earlier and was enhanced in $\mathrm{Chk}_{1}{ }^{\mathrm{del} /-}$ MEFs. In contrast, cyclin A2Cdk2 activity was not obviously affected by Chk1 depletion. Early and enhanced activation of cyclin A2-Cdk1 in $\mathrm{Chk} 1^{\mathrm{del} /-}$ MEFs appeared to be mediated by unregulated $\mathrm{Cdc} 25$ since the amount of $\mathrm{Cdc} 25 \mathrm{~A}$ was highly elevated and the subsequent fast mobility band of Cdk1 (active; Y15 dephosphorylation) was dominant in these cells.

Although hyperactivation of cyclin A2-Cdk1 and cyclin A2-Cdk2 in $\mathrm{Chk} 1^{\mathrm{del} /-} \mathrm{MEFs}$ suggests that cyclin A2-Cdk1 is a candidate trans-regulator of the origin firing program, it appears difficult to evaluate its specific role with regard to the cyclin A2-Cdk1 complex because cyclin A2 could form a complex with Cdk1 and Cdk2. Furthermore, Cdk1 is also capable of forming a complex with cyclin B and cyclin A. In order to examine the specific role of each cyclin-Cdk complex in the origin firing program, we generated cyclin A2-Cdk1, cyclin A2-Cdk2, and cyclin B1-Cdk1 fusion constructs. The properties of an active cyclinCdk fusion construct were successfully analyzed in the case of cyclin D1-Cdk2 (Chytil et al. 2004). Since cyclin-Cdk activities are regulated mainly by the phosphorylation of Y15, we generated a constitutively active mutant (CdkAF) in which residues at inhibitory phosphorylation sites were replaced with alanine and phenylalanine. Therefore, this mutant would not be affected by the Chk1-Cdc25 axis. Given that the enzymatic kinetic values of these fusion proteins were the same as those of the corresponding cyclin-Cdk complexes when histone $\mathrm{H} 1$ and lamin B were used as substrates (Table 1), the cyclin-Cdk fusion constructs were very useful for examining the specific roles of their corresponding complexes in vivo.

Expression of cyclin A2-Cdk1AF and cyclin A2$\mathrm{Cdk} 2 \mathrm{AF}$ fusion proteins at the endogenous level did not appear to affect overall $\mathrm{S}$ phase progression whereas that of cyclin B1-Cdk1AF induced severe $\mathrm{S}$ phase arrest with $\mathrm{gH} 2 \mathrm{AX}$ foci in HeLa cells. Double-labeling with IdU and CIdU in cells expressing cyclin A2-Cdk1AF allowed for the detection of late replication sites during early $\mathrm{S}$ phase (Fig. 2). Expression of cyclin A2-Cdk1AF fusion protein reduced origin spacing. These effects were not obvious in cells expressing cyclin A2-Cdk2AF fusion protein. Interestingly, expression of cyclin A2-Cdk2AF did not cause a significant induction of abnormal replication 
Table 1 Kinetic values for histone H1 and lamin B of cyclinCdk complexes and their fusion proteins

\begin{tabular}{lll}
\hline Enzyme & Histone H1 $(\mathrm{mM})$ & Lamin B $(\mathrm{mM})$ \\
\hline Cyclin A2-Cdk2 & & \\
Complex & 2.23 & 2.52 \\
Fusion & 2.06 & 2.09 \\
Cyclin A2-Cdk1 & & \\
Complex & 2.31 & 2.74 \\
Fusion & 2.25 & 3.25 \\
Cyclin B1-Cdk1 & & \\
Complex & 2.22 & 2.25 \\
Fusion & 2.18 & 1.82 \\
\hline
\end{tabular}

The purified cyclin-Cdk complexes or fusion proteins were incubated with the indicated substrates at varying concentrations. The phosphorylated substrates were separated by SDSPAGE and their incorporation was determined by radiography with a BAS-2000 imager

structures, unlike Chk1 depletion. These results clearly indicate that cyclin $\mathrm{A} 2-\mathrm{Cdk} 1 \mathrm{AF}$ is a trans-regulator of late origin firing, but is not likely to be involved in fork stabilization during $\mathrm{S}$ phase. Other downstream effectors of Chk1 might stabilize replication forks under both unperturbed and perturbed conditions.

\section{Cdk1 is required for proper timing of origin firing}

Recently, several reports have demonstrated the essential role of Cdk1 in $\mathrm{S}$ phase progression. In check DT40 cells, Cdk1 activity is essential for DNA replication initiation when Cdk2 is depleted (Hochegger et al. 2007). Cdk1 was found to have a similar role in DNA replication observed in Xenopus eggs (Krasinska et al. 2008). Elimination of Cdk1, Cdk2, or their partner cyclins alters replication origin spacing, mainly by decreasing the frequency of activation of origin clusters. We found that this is also the case with mammalian cells. FT210 cells harbor a temperaturesensitive Cdk 1 gene product and exhibit a $2 \mathrm{~h}$ longer $\mathrm{S}$ phase at a nonpermissive temperature when compared with the parental FM3A cells which possess a normal Cdk1 gene. Notably, late origin firing was severely impaired in FT210 cells at a nonpermissive temperature but not at a permissive temperature (Fig. 3). Loss of Cdk1 resulted in an increase in origin spacing but did not cause induction of an abnormal replication structure as it did in cells expressing cyclin A2Cdk1AF fusion protein.

Why would Cdk1 have a specific role in late origin firing? Cdk2 did not appear to complement Cdk1 function as a trans-regulator of these events. It should be noted that Cdk1 preferentially bound to late origins although both $\mathrm{Cdk} 1$ and $\mathrm{Cdk} 2$ bound to early origins. In yeast and Xenopus systems it was reported that cyclins and Cdk1 specifically interact with the origin recognition complex (Romanowski et al. 2000; Wuarin et al. 2002). A recent analysis of the temporal replication profile revealed the physiological impact of the temporal regulation of origin firing although half of the origins in this human study were formed a pan-S phase pattern with equivalent replication in all quarters of S phase (Jeon et al. 2005). These analyses also revealed the cis-factors that influenced replica-

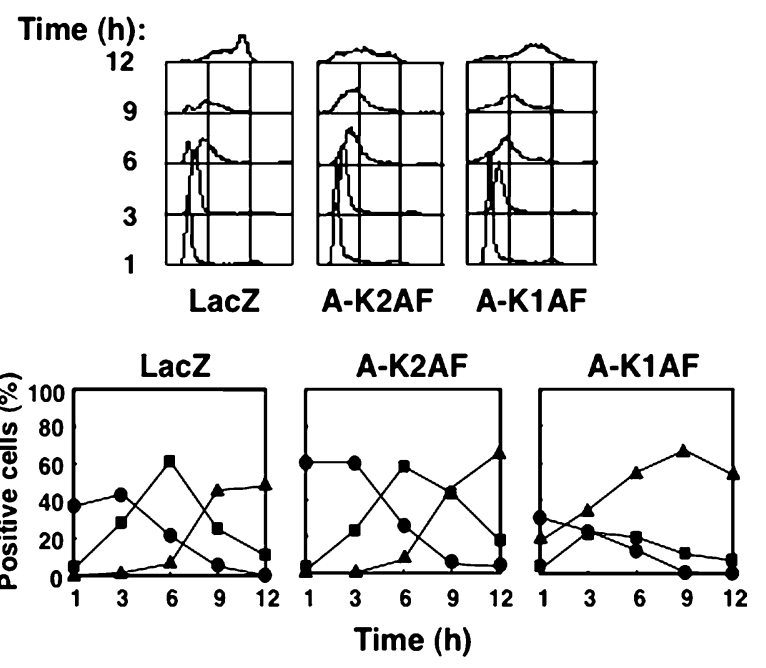

Fig. 2 Ectopic expression of cyclin A2-Cdk1AF, but not cyclin A2-Cdk2AF resulted in an aberrant temporal regulation of origin firing. HeLa cells were infected with adenoviruses expressing either cyclin A2-Cdk2AF, cyclin A2-Cdk1AF, or LacZ (control) $24 \mathrm{~h}$ before mimosine wash-out (time 0 ) and treated with $0.6 \mathrm{mM}$ mimosine $16 \mathrm{~h}$ before wash-out to synchronize cells at the G1/S boundary. Mimosine was washed out of the cell medium (time 0 ), then cells were harvested at the indicated times, and their cell cycle profiles were analyzed by FACScan (upper panels). Replication sites were pulse-labeled for 10 min with BrdU and analyzed by fluorescence microscopy. Typical replication site patterns are presented as early, middle, and late. The number of replication sites per pattern was counted and the number of positive cells relative to the total number of cells is expressed as a percentage (bottom panel). Filled circles represent the early pattern, filled squares the middle pattern, and filled triangles the late pattern 
Fig. 3 Essential role of Cdk1 in late origin firing. FT210 (mouse temperaturesensitive Cdk1 mutant cells) and the parental FM3A cells were synchronized at $\mathrm{M}$ phase by nocodazole treatment and then released into G1 phase at either a permissive $\left(33^{\circ} \mathrm{C}\right)$ or nonpermissive $\left(39^{\circ} \mathrm{C}\right)$ temperature. Cells were then harvested $6 \mathrm{~h}$ after release (time 0 ) and at various times thereafter. Their cell cycle profiles and replication sites were analyzed as described in the Fig. 2 legend

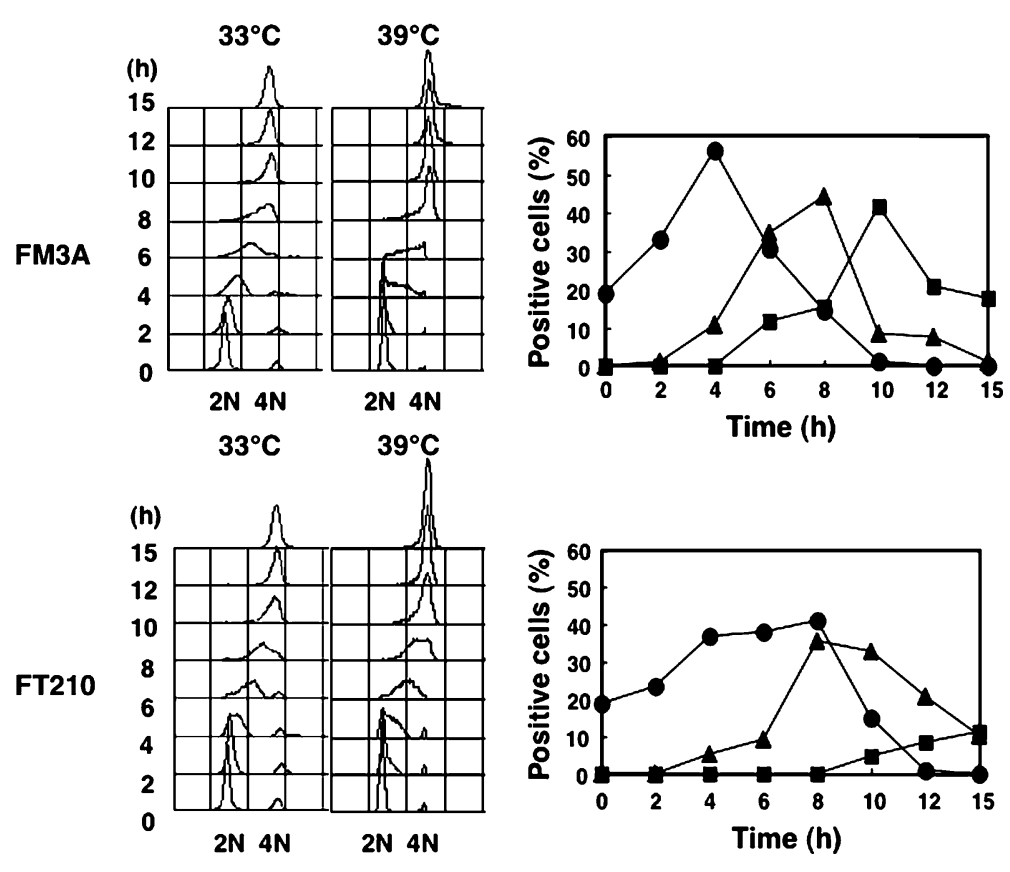

tion timing. In general, transcribed regions and regions rich in GC or alu are replicated early in the $\mathrm{S}$ phase. In contrast, gene-poor regions, heterochromatin, and regions with high concentrations of LINE repeats tend to replicate late. Taken together, some cis-factors including the chromatin status and gene density might affect the binding of Cdks to origins, leading to their preferential binding to late origins.

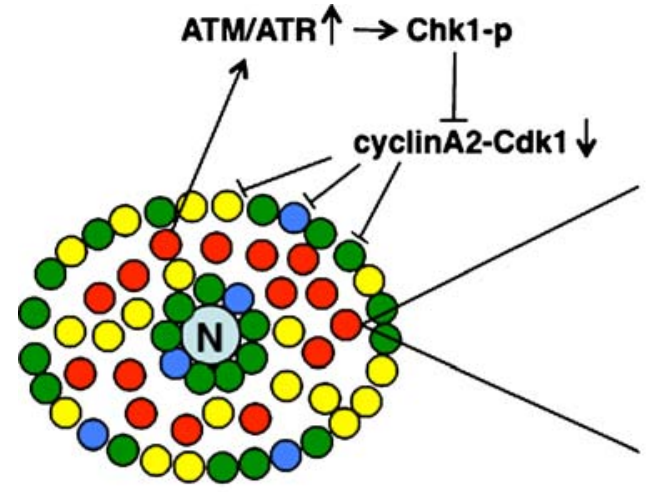

Early replicating foci

Middle replicating foci

Late replicating foci

Pan-S phase replicating foci

Fig. 4 Proposed model of origin firing program at two distinct levels regulated by the ATM/ATR-Chk1-cyclin A2-Cdk1 axis in mammals. The replication machinery utilizes an established path for sub-chromosomal foci during the temporal progression of $\mathrm{S}$ phase. The scheme depicts a cell nucleus harboring a nucleolus $(N)$ and DNA organized into sub-chromosomal foci. The spatial organization of the foci at specific replication times

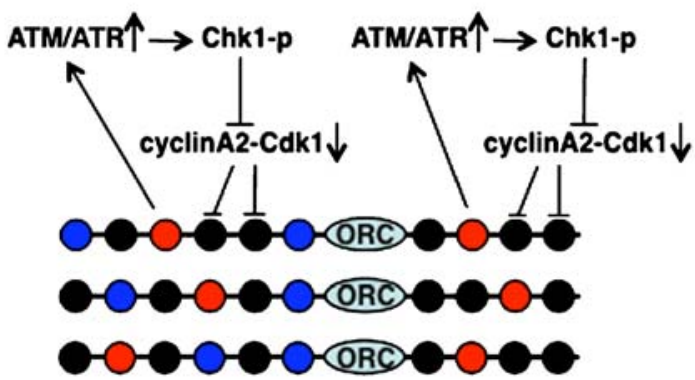

Initiated Mcm complex

Dormant Mcm complex

Passively initiated Mcm complex

is as follows: red early, green middle, blue late, and yellow pan S. Cyclin A2-Cdk1 appears to regulate two distinct stages in the origin firing program; one is the sequential activation of replicon clusters characterized as visible replication foci (left panel), and the other is the selection of one Mcm2-7 complex around the ORC within a single replication factory (right panel) 


\section{Conclusions and perspectives}

The key factors that regulate late origin firing are summarized in Fig. 4. Although there are some important differences between model systems, we propose that cyclin $\mathrm{A} 2-\mathrm{Cdk} 1$ has an essential role in late origin firing as a trans-regulator. The ATM/ATRChk1-Cdc25 axis regulates cyclin A2-Cdk1 activity in unperturbed $\mathrm{S}$ phase, ensuring the ordered firing of origins. This axis is very effective for slowing $\mathrm{S}$ phase progression in the presence of DNA damage or DNA replication blockage since ATM/ATR can recognize a wide variety of chromosomal abnormalities. Under unperturbed conditions, activated ATM/ATR phosphorylates Chk1 and subsequently suppressed activation of cyclin A2-Cdk1 which is required for late origin firing. Thus, checkpoint mechanisms likely target trans-regulators of the S phase program.

Although trans-factors of the $\mathrm{S}$ phase program would be expected to be conserved among eukaryotes since the DNA replication checkpoint underlies one of the basic mechanisms that prevent genomic instability during DNA replication, mechanisms for the regulation of origin firing in eukaryotes appear to be evolutionally diverse. Differential early or late firing of the various replication origins during $\mathrm{S}$ phase accounts for much of the temporal programming of replication in budding yeast. The temporal program is imposed by cis-acting chromosomal sequences which are distinct from the origins themselves. However, while cis-acting origin of the replication sequence is clearly defined in prokaryotes, it is ambiguous in eukaryotes. For example, a recent whole-genome analysis using $\mathrm{HU}$ revealed an $\mathrm{S}$ phase checkpoint in budding yeast that suppresses many origins characterized as late (Feng et al. 2006; Raveendranathan et al. 2006). However, only a few origins fire late during $S$ phase, and the Rad3-dependent $\mathrm{S}$ phase checkpoint has little effect on which origins are fired in fission yeast (Hayashi et al. 2007; Heichinger et al. 2006). Thus, the physiological significance of temporal regulation of origin firing in fission yeast remains somewhat unclear.

The physiological importance of the $\mathrm{S}$ phase program in mammals is an ongoing topic of interest, as is whether coordinated $\mathrm{S}$ phase programs prevent genomic instability during mammalian $\mathrm{S}$ phase. Very recently, an interesting observation has been made that the mutation rate, as reflected in recent evolutionary divergence and human nucleotide diversity, is markedly increased in late replicating regions of the human genome (Stamatoyannopoulos et al. 2009). Given that all classes of substitutions are affected by replication timing, an increased mutation rate appears to result from replication time-dependent DNA damage. These observations are also consistent with the finding that the SNP density is increased near later replicating genes. Therefore, these findings clearly suggest that in mammals, the origin firing program plays an important role in maintaining genome stability. Further studies are required to determine whether abnormalities in $\mathrm{S}$ phase programs lead to genetic instability diseases such as cancer or premature aging.

\section{References}

Bakkenist CJ, Kastan MB (2003) DNA damage activates ATM through intermolecular autophosphorylation and dimer dissociation. Nature 421(6922):499-506

Chytil A, Waltner-Law M, West R, Friedman D, Aakre M, Barker D, Law B (2004) Construction of a cyclin D1$\mathrm{Cdk} 2$ fusion protein to model the biological functions of cyclin D1-Cdk2 complexes. J Biol Chem 279(46):4768847698

Cleaver JE, Rose R, Mitchell DL (1990) Replication of chromosomal and episomal DNA in X-ray-damaged human cells: a cis- or trans-acting mechanism? Radiat Res 124(3):294-299

Courbet S, Gay S, Arnoult N, Wronka G, Anglana M, Brison O, Debatisse M (2008) Replication fork movement sets chromatin loop size and origin choice in mammalian cells. Nature 455(7212):557-560

DePamphilis ML (2003) Eukaryotic DNA replication origins: reconciling disparate data. Cell 114(3):274-275

Donaldson AD, Raghuraman MK, Friedman KL, Cross FR, Brewer BJ, Fangman WL (1998) CLB5-dependent activation of late replication origins in S. cerevisiae. Mol Cell 2 (2):173-182

Falck J, Mailand N, Syljuasen RG, Bartek J, Lukas J (2001) The ATM-Chk2-Cdc25A checkpoint pathway guards against radioresistant DNA synthesis. Nature 410 (6830):842-847

Feng W, Collingwood D, Boeck ME, Fox LA, Alvino GM, Fangman WL, Raghuraman MK, Brewer BJ (2006) Genomic mapping of single-stranded DNA in hydroxyureachallenged yeasts identifies origins of replication. Nat Cell Biol 8(2):148-155

Ge XQ, Jackson DA, Blow JJ (2007) Dormant origins licensed by excess Mcm2-7 are required for human cells to survive replicative stress. Genes Dev 21(24):3331-3341

Gilbert DM (2004) In search of the holy replicator. Nat Rev Mol Cell Biol 5(10):848-855

Goodarzi AA, Jonnalagadda JC, Douglas P, Young D, Ye R, Moorhead GB, Lees-Miller SP, Khanna KK (2004) 
Autophosphorylation of ataxia-telangiectasia mutated is regulated by protein phosphatase 2A. EMBO J 23(22): $4451-4461$

Harper JW, Elledge SJ (2007) The DNA damage response: ten years after. Mol Cell 28(5):739-745

Hayashi M, Katou Y, Itoh T, Tazumi A, Yamada Y, Takahashi T, Nakagawa T, Shirahige K, Masukata H (2007) Genome-wide localization of pre-RC sites and identification of replication origins in fission yeast. EMBO J 26(5):1327-1339

Heichinger C, Penkett CJ, Bahler J, Nurse P (2006) Genomewide characterization of fission yeast DNA replication origins. EMBO J 25(21):5171-5179

Hochegger H, Dejsuphong D, Sonoda E, Saberi A, Rajendra E, Kirk J, Hunt T, Takeda S (2007) An essential role for $\mathrm{Cdk} 1$ in $\mathrm{S}$ phase control is revealed via chemical genetics in vertebrate cells. J Cell Biol 178(2):257-268

Huberman JA (1998) DNA replication. Choosing a place to begin. Science 281(5379):929-930

Ibarra A, Schwob E, Mendez J (2008) Excess MCM proteins protect human cells from replicative stress by licensing backup origins of replication. Proc Natl Acad Sci U S A 105(26):8956-8961

Jackson DA (1995) Nuclear organization: uniting replication foci, chromatin domains and chromosome structure. Bioessays 17(7):587-591

Jeon Y, Bekiranov S, Karnani N, Kapranov P, Ghosh S, MacAlpine D, Lee C, Hwang DS, Gingeras TR, Dutta A (2005) Temporal profile of replication of human chromosomes. Proc Natl Acad Sci U S A 102(18):6419-6424

Jin J, Ang XL, Ye X, Livingstone M, Harper JW (2008) Differential roles for checkpoint kinases in DNA damagedependent degradation of the Cdc25A protein phosphatase. J Biol Chem 283(28):19322-19328

Katsuno Y, Suzuki A, Sugimura K, Okumura K, Zineldeen DH, Shimada M, Niida H, Mizuno T, Hanaoka F, Nakanishi M (2009) Cyclin A-Cdk1 regulates the origin firing program in mammalian cells. Proc Natl Acad Sci U S A 106 (9):3184-3189

Krasinska L, Besnard E, Cot E, Dohet C, Mechali M, Lemaitre JM, Fisher D (2008) Cdk1 and Cdk2 activity levels determine the efficiency of replication origin firing in Xenopus. EMBO J 27(5):758-769

Kumagai A, Lee J, Yoo HY, Dunphy WG (2006) TopBP1 activates the ATR-ATRIP complex. Cell 124(5):943-955

Lam MH, Liu Q, Elledge SJ, Rosen JM (2004) Chk1 is haploinsufficient for multiple functions critical to tumor suppression. Cancer Cell 6(1):45-59

Lamb JR, Petit-Frere C, Broughton BC, Lehmann AR, Green MH (1989) Inhibition of DNA replication by ionizing radiation is mediated by a trans-acting factor. Int $\mathrm{J}$ Radiat Biol 56(2):125-130

Machida YJ, Hamlin JL, Dutta A (2005) Right place, right time, and only once: replication initiation in metazoans. Cell 123(1):13-24

Mailand N, Falck J, Lukas C, Syljuasen RG, Welcker M, Bartek J, Lukas J (2000) Rapid destruction of human Cdc25A in response to DNA damage. Science 288 (5470):1425-1429

Marheineke K, Hyrien O (2004) Control of replication origin density and firing time in Xenopus egg extracts: role of a caffeine-sensitive, ATR-dependent checkpoint. J Biol Chem 279(27):28071-28081

Masumoto H, Muramatsu S, Kamimura Y, Araki H (2002) SCdk-dependent phosphorylation of Sld2 essential for chromosomal DNA replication in budding yeast. Nature 415(6872):651-655

Matsuoka S, Ballif BA, Smogorzewska A, McDonald ER 3rd, Hurov KE, Luo J, Bakalarski CE, Zhao Z, Solimini N, Lerenthal Y, Shiloh Y, Gygi SP, Elledge SJ (2007) ATM and ATR substrate analysis reveals extensive protein networks responsive to DNA damage. Science 316 (5828):1160-1166

Maya-Mendoza A, Petermann E, Gillespie DA, Caldecott KW, Jackson DA (2007) Chk1 regulates the density of active replication origins during the vertebrate $\mathrm{S}$ phase. EMBO J 26(11):2719-2731

Merrick KA, Larochelle S, Zhang C, Allen JJ, Shokat KM, Fisher RP (2008) Distinct activation pathways confer cyclin-binding specificity on cdk 1 and cdk2 in human cells. Mol Cell 32(5):662-672

Miao H, Seiler JA, Burhans WC (2003) Regulation of cellular and SV40 virus origins of replication by Chk1-dependent intrinsic and UVC radiation-induced checkpoints. J Biol Chem 278(6):4295-4304

Niida H, Nakanishi M (2006) DNA damage checkpoints in mammals. Mutagenesis 21(1):3-9

Niida H, Tsuge S, Katsuno Y, Konishi A, Takeda N, Nakanishi M (2005) Depletion of Chk1 leads to premature activation of Cdc2-cyclin B and mitotic catastrophe. J Biol Chem 280(47):39246-39252

Niida H, Katsuno Y, Banerjee B, Hande MP, Nakanishi M (2007) Specific role of Chk1 phosphorylations in cell survival and checkpoint activation. Mol Cell Biol 27 (7):2572-2581

Noguchi E, Shanahan P, Noguchi C, Russell P (2002) CDK phosphorylation of Drc1 regulates DNA replication in fission yeast. Curr Biol 12(7):599-605

O'Driscoll M, Ruiz-Perez VL, Woods CG, Jeggo PA, Goodship JA (2003) A splicing mutation affecting expression of ataxia-telangiectasia and Rad3-related protein (ATR) results in Seckel syndrome. Nat Genet 33(4):497-501

Painter RB, Young BR (1976) Formation of nascent DNA molecules during inhibition of replicon initiation in mammalian cells. Biochim Biophys Acta 418(2):146-153

Petermann E, Caldecott KW (2006) Evidence that the ATR/Chk1 pathway maintains normal replication fork progression during unperturbed S phase. Cell Cycle 5(19):2203-2209

Petermann E, Maya-Mendoza A, Zachos G, Gillespie DA, Jackson DA, Caldecott KW (2006) Chk1 requirement for high global rates of replication fork progression during normal vertebrate S phase. Mol Cell Biol 26(8):33193326

Raveendranathan M, Chattopadhyay S, Bolon YT, Haworth J, Clarke DJ, Bielinsky AK (2006) Genome-wide replication profiles of S-phase checkpoint mutants reveal fragile sites in yeast. EMBO J 25(15):3627-3639

Romanowski P, Marr J, Madine MA, Rowles A, Blow JJ, Gautier J, Laskey RA (2000) Interaction of Xenopus Cdc2 $\mathrm{x}$ cyclin A1 with the origin recognition complex. J Biol Chem 275(6):4239-4243 
Shechter D, Costanzo V, Gautier J (2004) ATR and ATM regulate the timing of DNA replication origin firing. Nat Cell Biol 6(7):648-655

Shiloh Y (1997) Ataxia-telangiectasia and the Nijmegen breakage syndrome: related disorders but genes apart. Annu Rev Genet 31:635-662

Shimada M, Niida H, Zineldeen DH, Tagami H, Tanaka M, Saito H, Nakanishi M (2008) Chk1 is a histone H3 threonine 11 kinase that regulates DNA damage-induced transcriptional repression. Cell 132(2):221-232

Smits VA, Reaper PM, Jackson SP (2006) Rapid PIKKdependent release of Chk1 from chromatin promotes the DNA-damage checkpoint response. Curr Biol 16(2):150159

Sorensen CS, Syljuasen RG, Lukas J, Bartek J (2004) ATR, Claspin and the Rad9-Rad1-Hus1 complex regulate Chk1 and $\mathrm{Cdc} 25 \mathrm{~A}$ in the absence of DNA damage. Cell Cycle 3 (7):941-945

Stamatoyannopoulos JA, Adzhubei I, Thurman RE, Kryukov GV, Mirkin SM, Sunyaev SR (2009) Human mutation rate associated with DNA replication timing. Nat Genet 41 (4):393-395

Stinchcomb DT, Struhl K, Davis RW (1979) Isolation and characterisation of a yeast chromosomal replicator. Nature 282(5734):39-43

Sun Y, Jiang X, Chen S, Fernandes N, Price BD (2005) A role for the Tip60 histone acetyltransferase in the acetylation and activation of ATM. Proc Natl Acad Sci U S A 102 (37):13182-13187

Takai H, Tominaga K, Motoyama N, Minamishima YA, Nagahama H, Tsukiyama T, Ikeda K, Nakayama K, Nakanishi M (2000) Aberrant cell cycle checkpoint function and early embryonic death in Chk1(-/-) mice. Genes Dev 14(12):1439-1447

Takai H, Naka K, Okada Y, Watanabe M, Harada N, Saito S, Anderson CW, Appella E, Nakanishi M, Suzuki H, Nagashima K, Sawa H, Ikeda K, Motoyama N (2002) Chk2-deficient mice exhibit radioresistance and defective p53-mediated transcription. EMBO J 21(19):5195-5205

Willis N, Rhind N (2009) Regulation of DNA replication by the S-phase DNA damage checkpoint. Cell Div 4:13

Woodward AM, Gohler T, Luciani MG, Oehlmann M, Ge X, Gartner A, Jackson DA, Blow JJ (2006) Excess Mcm2-7 license dormant origins of replication that can be used under conditions of replicative stress. J Cell Biol 173(5):673-683

Wuarin J, Buck V, Nurse P, Millar JB (2002) Stable association of mitotic cyclin $\mathrm{B} / \mathrm{Cdc} 2$ to replication origins prevents endoreduplication. Cell 111(3):419-431

Zou L, Elledge SJ (2003) Sensing DNA damage through ATRIP recognition of RPA-ssDNA complexes. Science 300(5625):1542-1548

Zou L, Stillman B (1998) Formation of a preinitiation complex by S-phase cyclin CDK-dependent loading of Cdc45p onto chromatin. Science 280(5363):593-596 